\title{
RESEARCH
}

Open Access

\section{Elementary content specialization: models, affordances, and constraints}

Kimberly A. Markworth ${ }^{1 *}$, Joseph Brobst ${ }^{1}$, Chris Ohana ${ }^{1}$ and Ruth Parker ${ }^{2}$

\begin{abstract}
Background: This study investigates the models of elementary content specialization (ECS) in elementary mathematics and science and the affordances and constraints related to ECS—both generally and in relation to specific models. Elementary content specialists are defined as full-time classroom teachers who are responsible for content instruction for two or more classes of students. The sample consists of 34 elementary content specialists in math and/or science, as well as a matched comparison group of self-contained classroom teachers. Participants participated in a focus-group interview and an online survey. Qualitative and quantitative analyses were performed to determine the models of ECS present in the sample and the affordances and constraints related to ECS as compared to traditional, self-contained classrooms.
\end{abstract}

Results: This research differentiates six models of specialization, characterized as within-grade team teaching, acrossgrade team teaching, and science as a special. Comparisons of data from math and science teachers engaged in ECS with self-contained teachers indicate that content specialization has affordances related to planning time, professional development, and instructional time. Constraints related to ECS include limitations on flexibility and the ability to collaborate with other teachers around content. No significant differences are found for time spent in transitions and most comparisons related to meeting the academic, social, and emotional needs of elementary students.

Conclusions: Engagement in ECS generally, and different models of ECS specifically, present various affordances and constraints. Differences between self-contained and ECS structures are magnified by certain models of specialization, such that these models can be placed along continua for these factors. There seems to be a trade-off with these factors in ECS implementation, such that easing the role of the teacher in one area amplifies it in another. A variety of factors may contribute to teachers' and administrators' decisions to engage in ECS. These continua of factors may support teachers and administrators in their decision-making as they consider alternative instructional arrangements to the traditional, self-contained model.

Keywords: Elementary teaching, Team teaching, Elementary mathematics, Elementary science, Content specialization, Departmentalization

Abbreviations: ECS, Elementary content specialization; EMS, Elementary mathematics specialist; ESS, Elementary science specialist

\footnotetext{
* Correspondence: kimberly.markworth@wwu.edu

${ }^{1}$ Western Washington University, Bellingham, USA

Full list of author information is available at the end of the article
} 


\section{Background}

Elementary teachers are expected to be generalists; they are required to teach all subject areas to their students in a self-contained classroom setting. Expert instruction in any content area requires deep content and pedagogical content knowledge and in-depth planning and keeping current with research takes time. Expert instruction-all day every day-is a tall order for elementary generalists, who are responsible for a minimum of five different content areas. Given the growing expectations for elementary mathematics and science instruction and the corresponding increase in demands on teachers, it is important that we investigate alternatives to the traditional model of elementary instruction.

Several educators argue for increased implementation of departmentalization, or content specialization, at the elementary level (Chan and Jarman 2004; Gerretson et al. 2008; Reys and Fennell 2003; Wu 2009). Potential advantages to content specialization have been identified for participating teachers. With teachers focusing on specific content, they can have additional time to develop cohesive lesson plans around a subject. Professional development can be targeted to specific content and the instructional practices that will enhance instruction. In addition, teachers can teach subjects that they are enthusiastic about and feel competent to teach. The potential advantages for students include increased access to expert instruction, ability to benefit from multiple teachers' teaching styles, and preparation for departmentalization that occurs in middle schools.

Beyond these general advantages, however, it is important to consider the advantages specific to mathematics and science. The expectation that all elementary teachers have the deep content knowledge and complex instructional skills needed to teach mathematics effectively limits students' access to quality mathematics instruction at the elementary level (Wu 2009). Although the same is true of science, this content area more often suffers from neglect as a subject that is not as frequently assessed as literacy and mathematics (Sandler 2003). Elementary content specialization (ECS) may provide a cost-effective alternative to the traditional self-contained classroom model, in which children may at times be taught by teachers who do not adequately understand the content themselves or who cannot provide instruction that allows students to engage in meaningful mathematics and science.

There is a dearth of research relating to ECS, in which full-time classroom teachers share students for the core content areas: reading, writing, mathematics, science, and social studies. Models in which elementary content specialists share students are fairly common (e.g., "team teaching"), yet the lack of empirical research regarding their effectiveness is problematic. The aim of this paper is to begin to fill this gap in the research literature. In this paper, we report on the results which are part of an ongoing exploratory research project to understand and categorize ECS models in relation to mathematics and science by describing ECS models that are being implemented for mathematics and science and examining the affordances and constraints of these models in comparison to self-contained classrooms.

\section{Review of the literature}

A self-contained classroom is the traditional model for elementary education, so rooted in history that investigations into its practice and impact are virtually non-existent. Justifications for this approach typically focus on the social and emotional needs of elementary students-teachers' opportunities to know and support "the whole child" (Heathers 1961). Supporters for self-contained classroom models emphasize the importance of the connection and stability provided by a single classroom teacher (Chan et al. 2009; Hood 2009). Because students spend the majority of their school day with the same teacher and in the same classroom, the teacher has an opportunity to know a child across many content areas and social situations.

The purpose of this paper is to examine alternatives to the traditional model for elementary instruction, their affordances, and their constraints. Although it is not uncommon for teachers, especially in the upper elementary grades, to engage in alternatives to the traditional model, there is very little research examining these models. In the following section, we summarize the current research related to models of ECS.

\section{Models of ECS}

Local anecdotal evidence and our own personal teaching experiences suggested that there would be substantial variation in models of ECS. Literature related to elementary mathematics specialists (EMS) and elementary science specialists (ESS) reveals varied uses of these terms. Schwartz and Gess-Newsome (2008) have broadly characterized different models of ECS in science as either teacher mentoring models or student instructional models. With teacher mentoring models, ESS are only partly responsible for science instruction; some of these positions are dedicated to instructional leadership and support for classroom teachers. In student instructional models, ESS teach full time, either in a departmentalized model as a member of a team teaching science to multiple classes of students, or in a model in which "the science specialist is responsible for planning and delivery of all science instruction, which typically takes place in a science laboratory or dedicated classroom" (p. 24).

Through a survey of representatives from six large school districts, Schwartz and Gess-Newsome (2008) found that all of these models were present across these districts, and that there was substantial variation within 
districts of the types of models in use. Half of the districts employed a combination of generalist models (self-contained classrooms), teacher mentoring models, and student instructional models. The remaining three districts indicated generalist models in combination with either of the two broad categorizations of specialist models.

This categorization of teacher mentoring models and student instructional models applies similarly to the use of the term elementary mathematics specialist (EMS). EMS includes educators who are serving as elementary mathematics teachers, intervention specialists, or coaches (McGatha and Rigelman, in progress). The last of these aligns with teacher mentoring models, while the first aligns with student instructional models. Although there is substantive and ongoing research on the effectiveness of EMS as coaches, research related to elementary mathematics teachers is almost nonexistent (McGatha 2009; McGatha et al. 2015).

Because this research focuses on alternatives to the traditional, self-contained model of elementary instruction, we exclude in the following sections research related to teacher mentoring models of content coaches and intervention specialists and focus instead on full-time classroom teachers who teach two or more classes of students in either mathematics or science. This distinction is especially relevant in mathematics, where EMS can refer to a teacher who has a special endorsement or certification. It is important to note that we focus on the roles of teachers filling an ECS position, rather than teachers with specific preparation or certification.

Review of ECS models revealed few descriptions of teaching arrangements beyond the broad categorizations of models discussed above. From a survey of principals in one large school district, Gerretson et al. (2008) found team teaching (defined here as two teachers sharing two classes of students) to be more prevalent in the upper elementary grades. Fewer than $3 \%$ of principals reported team teaching in primary grades $(\mathrm{K}-2)$, in contrast to 53 , 75 , and $78 \%$ of principals reporting team teaching in grades 3, 4, and 5, respectively. EMS in these positions frequently specialized in one additional subject area such as science (45\%) and social studies ( $25 \%)$ or the EMS specialized in only one subject area (25\%).

Studies with narrower foci often provide more detailed descriptions of ECS arrangements but are limited by the small scope of the research from making broader generalizations. For example, in a case study of ECS implementation in grades 1-3, Strohl et al. (2014) describe teams of two teachers, each responsible for specializing in content for two classes of students (science/social studies/mathematics; language/arts/reading/writing). This is the singular example in the literature of ECS in primary grades, in which students spend the morning of each day learning content with one teacher and the afternoon with the other teacher.

There can be substantial variation in how teams of teachers may be organized, both with the number of teachers and their content areas for specialization. However, as indicated by Schwartz and Gess-Newsome (2008), it is also possible to have ESS who are not members of particular teams of teachers. One study (Schwartz et al. 2000) describes a district in which an ESS in each elementary school teaches all science for students in grades 4-6. Students attend science for two 45-55 min lessons each week in a special laboratory classroom. In this model, the classroom teachers are expected to stay with their students for the science lesson to provide support.

Although team teaching may be a common term for the practice of grouping teachers to provide content instruction for multiple classes of students, another term is popular locally. The collaborative specialist model (Nelson and Landel 2007) describes a similar grouping of teachers but distinguishes itself from team teaching by its emphasis on deliberate selection of content specialization areas for teachers and strong collaboration around content and students. In the collaborative specialist model, teachers are selected for groups based on "their proven expertise in subject-matter content and pedagogy" (p. 74). The group of teachers is expected to collaborate across content areas for content integration, assessment, and examination of student learning. Although the collaborative specialist model may not describe an instructional arrangement that differs from the various team teaching situations identified above, it is important to recognize that there may be differential opportunities and expectations for collaboration between teachers who share students.

As a result of this review of the models of ECS, we anticipated that there would be distinct variations of team teaching with the number of teachers sharing students, the number of content areas in which each teacher specializes, and the content areas that may be combined for specialization, as well as additional models beyond team teaching. It is our goal to provide a finer grain size in categorization of models of ECS so that affordances and constraints of these models-both broadly and specifically-may be effectively examined.

\section{Affordances and constraints related to ECS}

The limited empirical research available suggests that ECS affords certain opportunities and presents various constraints for teachers. For example, principals in one district (Gerretson et al. 2008) indicated that the focus on fewer content areas with ECS afforded teachers greater time for planning, investigation and use of more resources, and a reduction in stress. Specialization also allowed greater focus with professional development, 
and principals believed that teachers' instruction and assessments were improved. Finally, principals reported greater collaboration between teachers for both content planning and for sharing students. From this administrative stakeholder lens, it seems that ECS can provide increased and focused opportunities for teachers to grow individually, as well as opportunities for teachers to collaborate that might otherwise not be available to selfcontained classroom teachers.

A case study of teachers in grades 1-3 implementing ECS reported similar results (Strohl et al. 2014). They found that ECS afforded more collaboration between teachers and multiple perspectives on students and their needs, for the benefit of the students. Although each teacher had more students through their team teaching model, teachers found assessment to manageable and more informative. Specialists reported a rigidity in the schedule that forced them to make better use of instructional time. They were more productive during their planning time, had more time to investigate resources, and felt that the model supported better instruction. In sum, the changes to their workload allowed them to focus their planning and instructional time in way that resulted in better instruction and greater satisfaction. Because ECS is so rare in the primary grades, it is important to note that the authors did not report any constraints as a result of the age level at which ECS was implemented in this school.

The opportunity to focus on specific content may have added affordances for ESS. In a study comparing the instructional practices of ESS and self-contained teachers, Schwartz et al. (2000) found that specialists' beliefs about science instruction were generally more in line with current reform efforts, specifically around the role of scientific inquiry in learning. In addition, specialists' instructional plans reflected these beliefs better than those of selfcontained teachers, whose instruction was generally geared towards lower-level knowledge through textbooks and teacher-centered instruction. In science, specialization seems to afford more opportunities to plan for inquiry-based experiences which may be more challenging to plan and implement for self-contained teachers with a divided focus.

One potential constraint of ECS models is the loss of instructional time due to transitions between classrooms. McGrath and Rust (2002) investigated the relationship between instructional model (self-contained versus ECS), instructional time, and between-class transition time through direct observation of the fifth and sixth grade students. Overall, they found no significant differences in instructional time, but the transition time for self-contained classrooms was significantly lower than that of students rotating between classrooms for content instruction. Limitations to this study were the small sample and limited number of observations; however, recording time through direct observation is a strength worth noting.
Overall, there is limited empirical evidence of the affordances and constraints that ECS provides in comparison to self-contained classrooms. Affordances related to teachers' time, planning, and quality of instruction are dominant, but there is some attempt to address concerns with specialization related to the teachers' ability to meet the needs of the whole child as well as time in transitions. The available research is limited by its broad descriptions of models, such that any affordances and constraints can only be characterized as related to a dichotomy: ECS versus self-contained. The aim of this research is to contribute to the empirical evidence of affordances and constraints for this dichotomy and examine how these may be modified with variation in models of ECS.

\section{Methods}

This research project employs both qualitative and quantitative research methodology to answer the following research questions:

1. What models of elementary content specialization (ECS) in mathematics and science are being implemented in local schools? What characteristics define these models?

2. What affordances and constraints exist in relation to ECS and ECS models, in comparison to a self-contained model?

In response to the first questions above, we use qualitative data to provide a description of ECS models that are in use in local school districts. In our discussion of the affordances and constraints, we use both qualitative and quantitative data to characterize and describe the factors associated with ECS models and the traditional, self-contained model.

\section{Participants \\ Specialists}

Over the course of two academic years (2013-2014 and 2014-2015), all EMS and ESS in full-time teaching positions from seven local school districts were invited to participate in this study: one urbanized area (population 50,000250,000) and six urban clusters (population 2500-50,000). All local districts in which elementary content specialization was occurring were invited to participate; all but one district consented to participate. Within these districts, EMS and ESS were identified as full-time classroom teachers in grades K-5 who taught two or more classes of students in either mathematics or science. Several teachers were identified as specialists in both mathematics and science and were invited to participate as double participants, completing all project activities for both content areas, except for the focus group interview. 
Thirty-four specialists from 15 elementary schools completed all data collection activities related to the research reported here. The elementary schools' student populations ranged from 206 to 536 students. Specialists' grade levels and assignments are reported in Table 1; these numbers represent the sample before attrition due to retirement $(n=1)$, changes in assignment to non-specialist positions in the second year $(n=4)$, leaving the profession $(n=1)$, and time concerns $(n=2)$. Because these specialists completed all data collection activities related to the research reported here, they are included in these findings and analyses.

In the final column of Table 1, percentages of the total specialist participants are provided. Note that $8.8 \%$ of the total participants are teachers in the primary grades (K-2), and $85.3 \%$ are teachers in the intermediate grades (3-5). These composite percentages do not include the two specialists assigned to teach both primary and intermediate grade levels.

\section{Comparison group}

Recruitment of a comparison group of teachers commenced in the first year of the study. A growing realization by the project team that attrition or changes in assignment would have a significant impact on the specialist group persuaded us to postpone rigorous recruitment of the comparison group until the second academic year, when the group of specialists and their assigned grade levels would be solidified.

The comparison group consists of self-contained elementary teachers: teachers who teach all core subjects to their class of students. Self-contained teachers were identified as potential participants through a two-step process. First, we identified schools with similar racial/ethnic compositions and free and reduced lunch percentages to the schools represented by specialists. Second, within these schools, teachers with a similar number of years of experience were sought as potential matches for the individual EMS and ESS at the matched schools. Although there was an attempt to identify schools within the same school district, this was often impossible.

The resulting comparison group includes teachers from five local school districts, three of which overlap with districts represented by the specialist group: one urbanized area, three urban clusters, and one rural (population less than 2500). The comparison group teachers represent 12 elementary schools: 10 unique elementary schools and 2 elementary schools that have participants in both the specialist and comparison groups. The elementary schools' student populations ranged from 176 to 480 students. The demographics of the specialist and comparison groups are reported in Table 2. Self-contained teachers were recruited as either science participants, math participants, or participants in both content areas. The content area invitation depended on the specialization of the specialist with whom the self-contained teacher was matched. The content and grade level of the comparison group are reported in Table 2. There was no attrition for this group over the more limited data collection period.

\section{Data collection}

Each participant participated in a focus group interview and an online survey. The focus group interview was

Table 1 Number of specialist and self-contained participants by grade level and content area

\begin{tabular}{|c|c|c|c|c|c|}
\hline Grade level & $\begin{array}{l}\text { No. of math } \\
\text { participants }\end{array}$ & $\begin{array}{l}\text { No. of double } \\
\text { participants }\end{array}$ & $\begin{array}{l}\text { No. of science } \\
\text { participants }\end{array}$ & Total & $\begin{array}{l}\text { Percentage of } \\
\text { group total }\end{array}$ \\
\hline \multicolumn{6}{|l|}{ Content specialist group } \\
\hline 1 & 1 & & & 1 & 2.9 \\
\hline 2 & & & 2 & 2 & 5.9 \\
\hline 3 & 1 & 2 & 1 & 4 & 11.8 \\
\hline 4 & 6 & 2 & & 8 & 23.5 \\
\hline 5 & 7 & 3 & 2 & 12 & 35.3 \\
\hline Multiple grades (1-4) & 1 & & 1 & 2 & 5.9 \\
\hline Multiple grades (4-6) & 1 & & 4 & 5 & 14.7 \\
\hline Total & 17 & 7 & 10 & 34 & 100 \\
\hline \multicolumn{6}{|c|}{ Self-contained comparison group } \\
\hline 1 & 1 & & 1 & 2 & 7.7 \\
\hline 2 & & & 2 & 2 & 7.7 \\
\hline 3 & 2 & & 2 & 4 & 15.4 \\
\hline 4 & 2 & 4 & 1 & 7 & 26.9 \\
\hline 5 & 5 & 3 & 3 & 11 & 42.3 \\
\hline Total & 10 & 7 & 9 & 26 & 100 \\
\hline
\end{tabular}


Table 2 Participant demographics by subject and teacher type

\begin{tabular}{lllll}
\hline Demographic & EMS & Math self-contained & ESS & Science self-contained \\
\hline Mean age (years) & 44.5 & 46.0 & 46.6 & 44.3 \\
Mean teaching experience (years) & 14.7 & 17.8 & 15.6 & 18.2 \\
Mean school \% FRL students & 54.4 & 54.6 & 48.4 & 52.5 \\
Mean school \% students of color $^{\mathrm{a}}$ & 40.1 & 36.3 & 35.3 & 36.7 \\
\hline
\end{tabular}

$F R L$ free and reduced lunch eligible

ancludes the following classifications: American Indian/Alaskan Native, Asian/Pacific Islander, Native Hawaiian/Other Pacific Islander, Black/African-American, Hispanic/Latino of any race(s), two or more races

intended to identify and describe various models of ECS at a qualitative level, as well as identify factors contributing to engagement (or lack of engagement) in ECS. The online survey was developed and used for the purposes of quantitative comparisons between the teacher groups and the ECS and self-contained models.

\section{Focus group interview}

Each participating teacher took part in an interview using a semi-structured interview protocol. When there were multiple teacher participants at the same school, they were invited to complete this activity in a focus group; otherwise, this was completed individually. Interviews were audio-recorded and transcribed.

In the semi-structured interview, teachers discussed various aspects of their models, what strengths they brought to their models, and the challenges and benefits associated with their models. However, if there were certain areas that were not addressed spontaneously by the participants, there were opportunities within the interview protocol to address them. For example, for the question, "How and why did you decide to pursue your current teaching model?", teachers were further prompted with questions related to the roles of administration; teachers; research, anecdotal evidence, or past experience; and standards (e.g., Common Core State Standards, Next Generation Science Standards). If teachers failed to address particular stakeholders when asked about challenges or benefits, they would be prompted to do so (i.e., themselves or other teachers, administration, students, parents). Finally, the semi-structured interview format allowed the interviewer to follow up during the conversation with additional questions for clarification or further exploration.

\section{Survey}

Each participating teacher completed a two-part online survey for each participating subject area (mathematics, science, or both). Special versions of the survey were constructed for double participants to remove redundant questions. Surveys included original questions as well as questions drawn from existing instruments, primarily the 2012 National Survey of Science and Mathematics Education (Horizon Research 2012). Initial questions on the survey related to demographics, educational and teacher preparation, teaching responsibilities, and factors related to current teaching position (e.g., student transitions, instructional and planning time, and collaboration with other teachers). Additional sections related to factors influencing the initial impetus and continuation of the specialist model; teacher beliefs about math and science instruction; enthusiasm and preparedness for subject areas; and professional development experiences and needs. Surveys took approximately $45 \mathrm{~min}$ to complete.

\section{Data analysis \\ Teacher interviews}

All interviews were transcribed and then coded using NVivo qualitative analysis software. The first two authors initially read all of the specialists' interviews and then co-developed a scheme in which transcripts were coded according to two lenses: a temporal lens and a stakeholder lens. We first coded responses to reflect whether the benefits, challenges, and other insights described by our participants were most relevant in the initiation stages of an ECS model or whether they represented ongoing lessons learned through extended engagement. For our stakeholder lens, we developed codes to reflect the interactions among stakeholders based on the content of the transcripts. Our set of stakeholder interaction codes consisted of interactions between teachers, students, administration, and parents.

Finally, after applying our temporal and stakeholder lenses, transcripts were further coded according to a combination of a priori themes addressed in our interview protocol (e.g., collaboration, curriculum, resources, and standards) and emergent themes from the transcript analysis (e.g., flexibility, continuity, and content integration). Data from this analysis was used to develop more robust understandings of the ECS models that were identified and triangulate the findings from the quantitative analysis of the surveys.

\section{Surveys}

Raw survey data were downloaded and processed, then inputted into the IBM SPSS Statistics 23 software package for analysis. Descriptive statistics were generated for results from each of the survey sub-tests. Where appropriate, 
comparisons between the means of specialist and selfcontained teachers' responses were conducted using independent sample $t$ tests along with integrated Levene's tests for equality of variances. All significance values were obtained via two-tailed tests.

\section{Results and discussion Models of ECS}

A primary purpose of this study is to provide classification and description of the variety of student instructional models (Schwartz and Gess-Newsome 2008) that are in use, yet not formally defined. Although the literature provides a few case descriptions of a few models (e.g., Strohl et al. 2014, discussed above), the research literature lacks more specified descriptions of student instructional models based on larger samples. It is our intent to provide a classification framework in the following section, based on our sample of math and science specialists.

Of the 34 specialists in this study, 29 participate in what has traditionally been called team teaching situations. These 29 teachers represent 23 unique teams of teachers (some specialist participants serve on the same team or replaced teachers who retired) from 16 different elementary schools. Five ESS participate in situations that we are calling science as a special. In Table 3 and the sections below, we detail the five models related to team teaching and the science as a special model.

\section{Team teaching}

Team teaching takes several different forms in this sample as identified by models A through E in Table 3. We use this term to describe situations in which teachers consider themselves to be coordinating with other teachers to deliver core content instruction to a "homeroom" plus one or two additional classes of students. Although the term departmentalization may be considered by some as appropriate here since teachers are focusing on a smaller number of content areas, we are avoiding this term, because teachers in all of these cases seem to associate themselves with the other teachers of the same students (a team), rather than other teachers of the same subjects (a content department). This term should not be confused with co-teaching, which often refers to teachers who work simultaneously in the same classroom to support students' learning. In addition, we are not using this term to refer to situations in which students are being tracked based on proficiency, unless this situation includes teachers who teach two or more classes of students in this content area.

In the following sections, we provide brief descriptions of four unique within-grade team teaching models (A through D); these four models account for 20 of the 23 teams of teachers. In our sample, there were a limited number of across-grade team teaching situations. Although it may be possible to further differentiate between across-grade team teaching models in a larger sample, we present them here as one model (E).

Team teaching-within grade level (models A through D) In our sample, we found that all but two of the team teaching situations involve arrangements in which teachers within one grade level were responsible, as a team, for the content instruction of a group of students. In all of these cases, the teams of teachers consist of two (models A and B) or three (models C and D) classroom teachers. Each teacher is assigned a group of students-a "homeroom"; together, these homerooms comprise the team of students for which these teachers share responsibility. In general, specialists in these models typically specialize in 1-3 content areas, teaching these to two or three classes of students on the team.

Our sample includes nine double participants-specialists who are responsible for both math and science instruction for two or more classes of students. An EMS or ESS may also specialize in non-STEM content, such as social studies or expository writing. In most cases, students move to the specialists' classrooms for content instruction. The singular example of the teachers moving between classrooms to provide instruction took place in a second grade team of two teachers, categorized as model A.

Model A

The first model is characterized by a team of two teachers, each of whom specializes in one content area. These two teachers share two classes of students at the same grade level, such that students from each class receive instruction in one content area from a content specialist. All other content areas are taught by the homeroom teacher. For example, in one second grade team teaching situation, there are two teachers: one ESS and one writing specialist. The students have a specialist for their writing and science instruction, but all other content is taught by their homeroom teacher. The content specialization of the other team teacher varies. Of the 3 EMS in this model, two did not teach reading and one did not teach science. Of the 2 ESS in this model, one did not teach reading and the other did not teach mathematics.

Of all of the team teaching models, students in model A are exposed to what is closest to the traditional selfcontained model of elementary instruction. Students are with a single teacher for most of the school day, and for most of the core content areas. For one content area each day, they are instructed by an ECS.

\section{Model B}

Model B is characterized by a team of two teachers who specialize in more than one content area. Two classes of students at the same grade level are shared between the two team teachers, and students from each 
Table 3 Models of elementary content specialization (ECS)

\begin{tabular}{|c|c|c|c|c|c|c|c|}
\hline & $\begin{array}{l}\text { No. of classes } \\
\text { of students }\end{array}$ & $\begin{array}{l}\text { No. of teachers } \\
\text { sharing students }\end{array}$ & $\begin{array}{l}\text { No. of EMS } \\
\text { and ESS in } \\
\text { this model }\end{array}$ & $\begin{array}{l}\text { Specialization in } \\
1 \text { content area } \\
\text { (math or science) }\end{array}$ & $\begin{array}{l}\text { Specialization } \\
\text { in more than } \\
1 \text { content area }\end{array}$ & $\begin{array}{l}\text { Content areas also } \\
\text { taught by EMS } \\
\text { and ESS }\end{array}$ & $\begin{array}{l}\text { No. of core } \\
\text { content preps } \\
\text { (teaching load) }\end{array}$ \\
\hline \multicolumn{8}{|c|}{ Within-grade team teaching } \\
\hline \multirow[t]{2}{*}{ A } & 2 & 2 & 3 EMS & $\checkmark$ & & $\begin{array}{l}\text { All, with the exception of: } \\
\text { - Reading }(2) \\
\text { - Science (1) }\end{array}$ & 4 \\
\hline & & & $2 \mathrm{ESS}$ & $\checkmark$ & & $\begin{array}{l}\text { All, with the exception of: } \\
\text { - Reading (1) } \\
\text { - Mathematics (1) }\end{array}$ & 4 \\
\hline \multirow[t]{3}{*}{ B } & 2 & 2 & 9 EMS & & $\checkmark$ & $\begin{array}{l}\text { 1-3 of the following: } \\
\text { - English literacy (3) } \\
\text { - Reading (1) } \\
\text { - Writing (1) } \\
\text { - Science (3) } \\
\text { - Social studies (3) } \\
\text { - Others: keyboarding, PE, technology, art (2) }\end{array}$ & $2-3$ \\
\hline & & & $2 \mathrm{ESS}$ & & $\checkmark$ & $\begin{array}{l}\text { 2-3 of the following: } \\
\text { - Spanish literacy (2) } \\
\text { - Math support in spanish (2) } \\
\text { - Social studies (1) }\end{array}$ & $2-3$ \\
\hline & & & 5 EMS/ESS & & $\checkmark$ & $\begin{array}{l}\text { In addition to math and science: } \\
\text { - Writing (1) } \\
\text { - Social studies (1) } \\
\text { - Others: technology, art (3) }\end{array}$ & $2-3$ \\
\hline C & 3 & 3 & 2 EMS & $\checkmark$ & & $\begin{array}{l}\text { Two of the following: } \\
\text { - Writing (2) } \\
\text { - Spelling (1) } \\
\text { - Others: art (1) }\end{array}$ & 2 \\
\hline \multirow[t]{2}{*}{$\mathrm{D}$} & 3 & 3 & 2 EMS & $\checkmark$ & & None & 1 \\
\hline & & & 2 ESS & & $\checkmark$ & $\begin{array}{l}\text { Share blocks of instruction with: } \\
\text { - Social studies (2) } \\
\text { - Word study (1) }\end{array}$ & 1 (at a time) \\
\hline \multicolumn{8}{|c|}{ Across-grade team teaching } \\
\hline \multirow[t]{3}{*}{$E$} & 2 or 3 & 2 or 3 & 2 EMS & $\checkmark$ & & $\begin{array}{l}\text { 1-3 of the following: } \\
\text { - Title support (1) } \\
\text { - Reading (1) } \\
\text { - Social studies (1) } \\
\text { - Art (1) }\end{array}$ & $2-4$ \\
\hline & & & $1 \mathrm{ESS}$ & $\checkmark$ & & $\begin{array}{l}\text { All of the following; } \\
\text { - Reading } \\
\text { - Social studies } \\
\text { - Art }\end{array}$ & 4 \\
\hline & & & 1 EMS/ESS & & $\checkmark$ & $\begin{array}{l}\text { None in addition to math } \\
\text { and science }\end{array}$ & 4 \\
\hline \multicolumn{8}{|c|}{ Science as a special } \\
\hline $\mathrm{F}$ & $4-14$ & Not applicable & 5 ESS & $\checkmark$ & & $\begin{array}{l}\text { None (2), or: } \\
\quad \text { - Technology (2) } \\
\text { - Reading (1) }\end{array}$ & $4-5$ \\
\hline
\end{tabular}

Note: Three double participants are classified in two different models, due to changing teaching assignments from year 1 to year 2 . For example, one ESS in year 1 is classified in model D, when he worked on a three-person team teaching science, social studies, and word study. In year 2, changing school numbers called for a two-person team, for which he taught math and science (model B). Because content-related surveys were completed at different times, we classified the 2 years as different model

class receive instruction in two or more content areas from each of these teachers. The greatest number of specialist participants fall into this category, making a team teaching model with two teachers at the same grade level the most prevalent model in our sample. Additional content areas of specialization vary significantly for 
specialists in this model. Most teachers in this model specialize in two core content areas. Two EMS specialize in Science and Social Studies by sharing a time block for these two content areas; three additional EMS specialize in three core content areas as part of a dual language program.

Students engaged in a model B team teaching context have two main classroom teachers for the core content areas. They are instructed by each teacher in two or more content areas, thus spending a more balanced amount of time with each of the team teachers. Students in this model will often spend "blocks" of time with their teachers, which are parsed into content instruction. For example, a student in model B might spend the morning with one teacher in literacy and social studies instruction and the afternoon with the second teacher in math and science instruction. Other students on this team would have these blocks reversed.

This category includes five participants from a dual language school who specialize in either mathematics or science. These teachers are assigned to teach particular content in English or Spanish, based on the Dual Language Enrichment Model of Gomez and Gomez (2015). In contrast to other dual language programs, "this model does not call for instruction in all subjects [sic] areas in both languages. Instead, it requires that all learners regardless of language background learn certain subjects only in the minority language, while others are learned only in the majority language" (Gomez and Gomez 2015, emphasis original). Thus, EMS at this school teach mathematics in English, while ESS teach science in Spanish.

\section{Model C}

This model is characterized by three teachers sharing three classes of students at the same grade level. This study's sample includes two EMS in this model from a larger elementary school; these teachers are able to focus almost exclusively on mathematics by teaching this content to three classes of students. Specialists in this model take on limited additional content areas (e.g., writing and spelling), but only for their homeroom class. The other specialists on the team specialize in reading or science/social studies.

Students who are engaged in this model will have three teachers for core content areas. Content instruction is typically arranged in three blocks, with one block being longer than the others to accommodate the additional content instruction from the homeroom teacher. For example, a student may have an extended block of instruction with her homeroom teacher for math, writing, and spelling and shorter blocks of instruction with two other teachers for science/social studies and reading.

\section{Model D}

Model D is also characterized by three teachers sharing three classes of students at the same grade level. In contrast to model $\mathrm{C}$, however, specialists in this model are only responsible for teaching one content area at a time. Our sample includes two EMS who are responsible for mathematics instruction for three classes every day of the school year and two ESS who are responsible for both science and social studies. Rather than dividing a daily instructional block between two content areas, ESS alternate one unit or time period (e.g., semester or quarter) of science with one unit or time period of social studies. Thus, the ESS specialize in more than one content area but are responsible for only one content area at any given time.

Students in a model D team teaching context have three main classroom teachers, from whom they receive three equivalent blocks of instruction in math, science/social studies, and literacy. For example, a student may have literacy instruction from his homeroom teacher and two equivalent blocks of instruction in math and science/social studies from two other team teachers each day.

Team teaching-across-grade levels (model E) In across-grade level team teaching, two or three teachers share instruction for an equivalent number of classes of students at different grade levels. This study's sample includes one ESS, two EMS, and one double participant who service students across two grade levels (two teams with grades 4 and 5; one team with grades 2 and 4). Specialists in this team teaching situation may teach multiple classes of mathematics or science, but these lessons are not repeating lessons, because the content is at different grade levels.

Both of these schools where across-grade level team teaching is taking place are fairly small elementary schools (280 and 206 students in grades K-5, respectively). Student numbers from year to year at each grade level can fluctuate, resulting in combination classes (e.g., grades $4 / 5)$ and position changes for teachers. In fact, in the second year of our study, the student number at one school changed such that there were enough students for two classes at each grade level; as a result, the across-grade level specialization transformed into within-grade level (model B). At another school, the EMS position changed with fluctuating student numbers, such that she is no longer qualified as an EMS.

\section{Science as a special (model F)}

This model of elementary science specialization occurred in two local districts but was dominant in one of the local districts in this research. In this model, science teachers have schedules similar to teachers of "special" subjects, such as art, music, physical education, and library. This model is similar to the science specialist position described by Schwarz et al. (2000). Elementary teachers of these special subjects often teach a large 
proportion of the student population, if not the whole student population. Students are scheduled to see these specialists 1-2 times per week. This time is often considered prep time for the students' regular classroom teachers, who are not responsible for the students' education in these particular content areas.

In this model, science is treated as a special subject, taught by science teachers. Students attend this class just as they do other specials, in some cases with more frequency or total time allotment than other specials. In three cases that are included in this study, students in grades 3-6 or 4-6 are assigned to up to three $45-\mathrm{min}$ science blocks each week. One school arranged the schedule such that students have two consecutive science blocks. This schedule enables the ESS to implement some of the more time-consuming laboratory activities during these double blocks. In the fourth case at a small elementary school (approximately 200 students), all science for students in grades $1-4$ (year 1 of the study) or grades $1-3$ (year 2) is taught by a single teacher who also has the following responsibilities: math support for a beginning teacher (year 1), science instruction for resource room students (year 2), and technology instruction (both years).

\section{Affordances and constraints of ECS models}

Changes to the traditional, self-contained model of elementary instruction have various and interrelated impacts on factors related to instruction. Further distinction between models of ECS provides an opportunity to examine the differentiated impacts of these models. In the following sections, we discuss affordances and constraints both generally (ECS versus self-contained) and, when possible, in respect to the models that are defined in Table 3.

We have identified four general areas which may exhibit a differentiated impact of ECS models: number of content areas, number of "preps," number of students, and the potential number of transitions between classrooms for students. Despite our finding of six models of ECS, there is still substantial variation within these models. These variations make quantitative generalizations impossible; however, we can examine how these models fall on continua for these areas in relation to each other and in comparison to self-contained classrooms (Fig. 1).

Self-contained classrooms fall high on the continua for the number of content areas and the number of "preps." Because self-contained teachers teach all core content areas to their students, they are responsible for all of these content areas and preparing for each of these content areas on a daily basis (or as often as the content is taught). In contrast, self-contained classrooms fall low on the continua for the potential number of transitions between classrooms and number of students. With the exception of special subjects, self-contained teachers have their one class of students with them in the one classroom for the entire day. In the following sections, we discuss each of these areas in which variation may occur in relation to the models we have identified. Supporting evidence from teacher interviews and surveys is provided.

\section{Number of content areas and number of preps}

In comparison to the self-contained model, models of ECS allow teachers to focus on fewer content areas. Teachers in model A only specialize in one content area, thereby "giving up" one content area to their team partner. This relieves them of one content area, placing this model slightly below self-contained on the continuum (Fig. 1). Teachers in models B, C, and $\mathrm{E}$ have fewer content areas on which to focus, because they either

\begin{tabular}{|c|c|c|c|c|}
\hline No. of Content & $\mathrm{D}, \mathrm{F}$ & $\mathrm{B}, \mathrm{C}, \mathrm{E}$ & A & $\begin{array}{c}\begin{array}{c}\text { Self- } \\
\text { Contained }\end{array} \\
\stackrel{\overbrace{}}{\longrightarrow}\end{array}$ \\
\hline No. of "Preps" & D & $\mathrm{B}, \mathrm{C}$ & $\mathrm{A}, \mathrm{E}, \mathrm{F}$ & $\begin{array}{c}\text { Self- } \\
\text { Contained }\end{array}$ \\
\hline $\begin{array}{l}\text { Potential No. of } \\
\text { Transitions between } \\
\text { Classrooms }\end{array}$ & $\ll \begin{array}{c}\text { Self- } \\
\text { Contained }\end{array}$ & $\mathrm{A}, \mathrm{F}$ & $\mathrm{B}, \mathrm{E}$ & C, D \\
\hline No. of Students ${ }^{*}$ & $\begin{array}{c}\text { Self- } \\
\text { Contained }\end{array}$ & $\mathrm{A}, \mathrm{B}$ & C, D & $\mathrm{F}$ \\
\hline $\begin{array}{r}\text { *Specialists in mode } \\
\text { been excluded from } \\
\text { Fig. } 1 \text { Continua for factors related to mode }\end{array}$ & $\begin{array}{l}\text { may be respon } \\
\text { is continuum. } \\
\text { of ECS }\end{array}$ & $r$ either twc & aree classes & dents, and have \\
\hline
\end{tabular}


specialize in more than one content area (B, some $\mathrm{E})$ or teach more classes of students $(\mathrm{C}$, some $\mathrm{E})$, thus relieving them of additional content areas. The lowest on this continuum are models $\mathrm{D}$ and $\mathrm{F}$, in which teachers are responsible for very few content areas. Most specialists in models $\mathrm{D}$ and $\mathrm{F}$ are responsible for one content area, although this number may be slightly higher for some specialists.

The number of content areas typically coincides with the number of preps for teachers. That is, with fewer content areas to teach, a specialist has fewer unique lessons to prepare for each day. On the continuum for the number of preps (Fig. 1), this is generally true, with the exception of models $\mathrm{E}$ and $\mathrm{F}$; these models are shifted towards a greater number of preps, due to the number of grade levels for which these specialists prepare. Despite content specialization, these specialists may have almost as many preps as a self-contained teacher. Thus, there seems to be a distinct trade-off that occurs with these two models: specialists have an ability to focus on particular content areas, without a significant reduction to the number of preps.

In the focus group interviews, most specialists discussed the benefits of being able to focus on fewer content areas, in contrast to all of the content areas for which selfcontained teachers need to prepare. This content focus seems to have multiple, interrelated impacts on specialists' ability to plan and implement quality instruction, to know and teach to standards, and to develop and investigate resources.

These impacts are challenging to tease apart. For example, Cole (double participant, model B) considers the number of standards that students are expected to master within a year:

Cole: We're always asked to go a mile wide and teach so many standards. At one time I was teaching fifth grade there were 122 standards the kids had to be able to do. I always felt like if I could focus on certain content that I could teach it better without having to deal with all the other content areas that I taught.

In this quote, Cole suggests that his ability to focus his attention on fewer standards leads to a better quality of instruction in his classroom. Similarly, Julia (ESS, model B) equates the relief from other content areas as a factor that contributes to her own development of resources and improved instruction.

Julia: You can spend most of your research time and time developing and creating lessons to be targeted to that one specific content, versus having to do a little bit of this and a little bit of that. So not having a whole lot of responsibility with the math has given me that extra time. By doing so, I believe that my students benefit, because they get a specialized teacher in science, who's a lot more prepared and a lot more ready to teach that content in depth versus just scratching the surface all the time.

For many specialists, like Julia, the common thread to these impacts seems to be time.

Planning time Self-contained teachers have limited time to prepare for all of the content areas that they teach. Relief from preparing for one content area seems to free up time for content areas of specialization. Amy (EMS, model D) explained how additional time has an impact on specialists' understanding of standards, investigation of resources, and quality of instruction:

Amy: I think it's really helpful just to be able to have more time to plan and really dig deeper into the standards, just because they are increasingly...I don't know...more intense and there's so much to it. It's just not as basic anymore so you can really dig in deeper and find cooler activities, more interactive activities than just doing a worksheet or something on paper. I don't know. I spend a lot more time planning.... This way all my time is focused on math and increasing student understanding. Where before it's like, "Okay. We'll do the best we can and move on."

Time was such a frequent reference that a broad "TIME" code was added to the qualitative analysis of the interview data. This code, applied 90 times in the specialists' interviews, was cross-coded $55.6 \%$ of the time with codes related to the teacher as a stakeholder. Of these, $86 \%$ related to the teachers' ability to plan for and cover content and keep up with curriculum, resources, and standards, and classroom responsibilities. It seems that challenges related to time are most closely associated with planning for the everyday instruction in the classroom. When there are fewer content areas for which to plan, teachers recognize its impact on their time availability.

\section{Individual planning time}

Through the online survey, we collected quantitative data about specialists and self-contained teachers' planning time for their mathematics and science instruction. In the first row of data in Table 4, we provide the mean number of minutes spent planning for content-specific instruction for specialists and self-contained teachers. The differences for both content areas are significant at the $p=0.05$ level; EMS and ESS spend significantly more time planning for math and science instruction than self-contained teachers. 
Table 4 Individual and collaborative planning time

\begin{tabular}{|c|c|c|c|c|}
\hline & \multicolumn{2}{|l|}{ Math } & \multicolumn{2}{|c|}{ Science } \\
\hline & EMS M & Self-contained $M$ & ESS M & Self-contained $M$ \\
\hline Minutes spent planning for mathematics/science instruction per week & $270^{* *}$ & $159^{* *}$ & $397^{*}$ & $72^{*}$ \\
\hline $\begin{array}{l}\text { Minutes of common planning time with other mathematics/science } \\
\text { teachers per week }\end{array}$ & $21^{*}$ & $75^{*}$ & 12 & 44 \\
\hline $\begin{array}{l}\text { Minutes of after-school instructional planning with other } \\
\text { mathematics/science teachers per week }\end{array}$ & 23 & 28 & 11 & 9 \\
\hline \multicolumn{5}{|l|}{$\begin{array}{l}\text { Stem: Please provide your opinion about each of the following } \\
\text { statements: } 1 \text {-strongly disagree } 6 \text { - strongly agree }\end{array}$} \\
\hline I have enough time to plan for all of the subjects I teach. & $2.92^{* * *}$ & $1.41^{* * *}$ & $2.95^{* *}$ & $1.69^{* *}$ \\
\hline I have enough time to plan for my math/science instruction. & $3.25^{*}$ & $2.34^{*}$ & 3.05 & 2.56 \\
\hline $\begin{array}{l}\text { I have enough time to investigate available math/science } \\
\text { instructional materials beyond what my district has provided. }\end{array}$ & 2.21 & 1.65 & 2.26 & 1.56 \\
\hline $\begin{array}{l}\text { I have enough time to meet with other teachers about } \\
\text { math/science instruction. }\end{array}$ & 2.83 & 2.94 & 2.37 & 2.38 \\
\hline
\end{tabular}

Note: ESS mean for minutes spent planning was skewed by specialists in model F. The mean for ESS in models A, B, D, and E is 164 min; this difference is also statistically significant

${ }^{*} p<0.05 ;{ }^{* *} p<0.01 ;{ }^{* * *} p<0.001$

Although most specialists indicated that their planning time was better spent by planning for fewer courses, there were conflicting results regarding the effect of specialization on the amount of time needed to plan effectively. Several specialists indicate that they spend the same amount of time on preparation as self-contained teachers, but the specialized content areas are getting more time allocated to them. This allows for better familiarity with standards and more investigation into curriculum and resources:

Melia (double participant, model E): I think you can plan deeper lessons so it's not like I don't...if say a 45 minute planning day, I don't feel like, "Well now I only need 30 because I'm teaching the same thing twice." I'm able to take that lesson deeper. I still need the same amount of time. Does that make sense?

In contrast, a few specialists indicate that the specialization actually saves them preparation time.

Jim (double participant, model B): It does take off some of the planning, because instead of having to prep for the entire day a different thing throughout the day so you're prepping four or five different things, I'm just prepping for two things - reading and math - and I just do it twice.... It makes life easier in that regard.

These contrasting opinions indicate that although specialists find ECS beneficial to their ability to plan for their classes and the time that it takes to do so, there is some discrepancy in how this benefit is viewed. The majority of specialists indicate that they invest the same amount of planning time but use this time to plan deeper or accommodate the increased number of students. Two specialists find that time spent on planning is reduced, making their jobs easier.

Also in Table 4, we summarize teachers' self-report data from the survey on prompts related to having enough time to plan for all their content areas, to plan for mathematics or science instruction, to investigate additional resources, and to meet with other teachers about mathematics or science instruction. The first of these factors is significant for both mathematics and science, such that specialists are more likely to report having enough time to plan for all of the subjects they teach. It is important to recognize that, even for these specialists, the mean is low, less than 3 for both content areas on a 1-6 scale. In mathematics, EMS are significantly more likely to report having enough time to plan for their mathematics instruction. Although not statistically significant, specialists also are more likely to report having enough time to investigate additional resources related to their mathematics or science instruction. Thus, the specialists' indications of having more specialized content-focused planning time and the affordances that this provides are supported by the self-report survey data.

\section{Collaborative planning time}

Differences in collaborative planning are, for the most part, not statistically significant (Table 4). Self-contained teachers have more common planning time with other teachers who also teach mathematics and science than specialists do, but this difference was only significant for mathematics. One explanation of this disparity in common planning time may be that models of ECS reduce the number of mathematics and science teachers in the 
schools; although there may be common planning time with other teachers at the same grade level, collaboration around specific content may not be possible.

Specialists indicate that being the sole person responsible for a particular content area within a grade level or team can be challenging because of this lack of opportunity for content collaboration. Jim describes the shift in collaboration between himself and a team teacher as a result of the school's movement to a team teaching model:

\section{Jim: In previous years when we both taught} everything, it was easier for us to collaborate because we'd get together and talk about math and how we're teaching the kids. But this year, because I am the fifth grade math teacher, there's not really another fifth grade math teacher to go talk to.... We get together to talk about specific students a lot of times.... But for content, I'm pretty much on my own here at the school.

Similarly, Amy describes how the nature of collaboration shifted after she became an EMS and how this shift left her feeling isolated within her content area. Other specialists emphasize the change in the nature of the collaboration from content to students. For example, Salome (ESS, model D) explains that her team of three teachers discusses students extensively, as well as other broad education practices, such as formative assessment and guiding questions.

Professional development Finally, a focus on fewer content areas was also referenced in regards to experience with content-specific professional development. Although these professional development experiences were often referenced as prior work, specialists also indicate that the content specialization enabled them to focus their ongoing professional growth and make meaningful changes to their classroom instruction. For Leah (double participant, model B), ECS allows more opportunity for change to take place:

Leah: And I think the specialist model - especially for intermediate - because there's so many things that teachers have to know really deeply that making change is hard when you're trying to make change in so many different subject areas.

Teachers who teach all content areas may find it slow to make significant, positive changes to their classroom instruction. In contrast, teachers who teach a content area multiple times not only have the repetition of the lesson as an opportunity for reflection and change, but also an ability to focus their change on a greater proportion of their practice.

\section{Potential number of transitions between classrooms}

One area of concern regarding the implementation of ECS is the instructional time that is lost when students switch between classrooms (McGrath and Rust 2002). The selfcontained model requires no additional between-classroom transitions, other than the ones typically required for lunch, recess, and specials. Thus, self-contained is at the lowest point on this continuum in Fig. 1. In models $\mathrm{A}$ and F, students may have more between-classroom transitions to accommodate for seeing an additional teacher. Models B and E may be greater still, depending on the number of times that students transition to and from the other teacher in model B and the number of teachers in model E. Finally, model $\mathrm{C}$, with three different teachers, means that students will be transitioning to and from at least two additional classrooms during the day.

Questions on the survey collected data related to this concern, querying specialists and self-contained teachers about the number of between-classroom and within-class transitions each day and how many minutes on average these transitions take. These data were consolidated into two measures for specialists and self-contained teachers: total minutes of between-classroom transition time per day and total minutes of within-class transition time per day (Table 5). Statistical comparisons of these measures indicate that there are no significant differences in the time spent in transitions for students in models of ECS and students in self-contained classrooms. In several surveys, specialists explained that their schedules were arranged to capitalize on transitions already occurring during the day. For example, a team of teachers might switch students after specials, recess, or lunch in order to minimize instructional time lost in transition.

Instructional time Another question asked teachers to quantify the number of minutes spent in mathematics or science instruction each week for each class. The difference between specialists and self-contained in mathematics is not significant. However, for science, students who are taught by specialists receive significantly more minutes of instruction $(M=186)$ than students assigned to self-contained classrooms $(M=109)$. It seems that the act of assigning a science specialist makes more time for science as a content area; this may have additional impacts on science instruction. The ability to go in depth with science content may be amplified by the amount of time that students receive in science instruction:

Lena: We have four lessons per week in science which I've never been able to achieve with our regular model.... I'm teaching more science and that's a good thing.

Lena (double participant, model B) recognizes that ECS enables her to simply fit in more time for science. 
Table 5 Time spent in transitions and mathematics/science instruction

\begin{tabular}{|c|c|c|c|c|c|c|c|c|}
\hline & \multirow{2}{*}{$\begin{array}{l}\text { ECS } \\
M\end{array}$} & \multirow{2}{*}{$\begin{array}{l}\text { Self-contained } \\
M\end{array}$} & \multicolumn{6}{|c|}{$M$ by ECS model } \\
\hline & & & $\bar{A}$ & B & $\mathrm{C}$ & $\mathrm{D}$ & E & $\mathrm{F}$ \\
\hline \multicolumn{9}{|l|}{ Mathematics } \\
\hline Total minutes of between-classroom transition time per day & 27 & 29 & 24.0 & 25.4 & 37.8 & 32.3 & 26.3 & \\
\hline Total minutes of within-classroom transition time per day & 11 & 15 & 11.7 & 10.8 & 9.0 & 8.5 & 11.0 & \\
\hline $\begin{array}{l}\text { Minutes spent per class of students in mathematics instruction } \\
\text { per week }\end{array}$ & 361 & 331 & 326.7 & 376.8 & 300.0 & 397.5 & 340.0 & \\
\hline \multicolumn{9}{|l|}{ Science } \\
\hline Total minutes of between-classroom transition time per day & 24 & 22 & 20.0 & 25.0 & & 26.5 & 21.5 & N/A \\
\hline Total minutes of within-classroom transition time per day & 11 & 13 & 11.0 & 15.3 & & 3.0 & 11.8 & 4.9 \\
\hline Minutes spent per class of students in science instruction per week & $186^{*}$ & $109^{*}$ & 242.5 & 164.4 & & 240.0 & 280.0 & 138.8 \\
\hline
\end{tabular}

NA Not Available

${ }^{*} p=0.001$

It is possible that the different models provide different opportunities to increase instructional time in mathematics and science or reduce the number of betweenclassroom transitions. In Table 5, we have disaggregated the data by model. Although statistical significance comparisons are not appropriate for the small number of participants in some of the models, notable quantities are highlighted in bold. In mathematics, it is interesting to note that the between-classroom transition time is highest for models $\mathrm{C}$ and $\mathrm{D}$, and the within-classroom transition time is lowest for models A and B. In science, the greatest amount of instructional time is accomplished with models $\mathrm{A}, \mathrm{D}$, and $\mathrm{E}$, and the means of all models exceed the mean for self-contained classrooms. In mathematics, models B and $\mathrm{D}$ have the greatest amount of instructional time, whereas models $\mathrm{A}$ and $\mathrm{C}$ report less instructional time than self-contained classrooms.

\section{Number of students}

Any model of ECS will have one certain impact: the specialist will be responsible for teaching more students. In a self-contained setting, the teacher is responsible for instruction in all content areas but is only responsible for the single class of students. This responsibility increases with the number of classes for which a specialist is responsible. In models $\mathrm{A}$ and $\mathrm{B}$, each specialist sees two classes of students; in models $\mathrm{C}$ and $\mathrm{D}$, the specialist sees three classes of students. (Specialists in model $\mathrm{E}$ may be responsible for either two or three classes of students and have been excluded from this continuum.) Model F, especially in the one district where this model is implemented in all elementary schools, results in the greatest number of students per ESS.

In our qualitative analysis, we found evidence that the increased number of students for ESS in model F corresponded with increased challenges with assessment and classroom management. One ESS in this model reported that she was responsible for some content instruction (in science or other content areas) for 350 students. Specialists in this role are responsible for assessing up to six classes of students in science. According to one science specialist, this task-providing quantitative and qualitative assessment data for so many students-led to the change to pass/fail science scores in the district implementing this model.

This quantity of students and the relative infrequency of seeing them present challenges with classroom management. One specialist in her first year indicated that she was still learning students' names and that classroom management was an unanticipated challenge:

Lori (ESS, model F): In science when I see so many kids, classroom management is a challenge because you don't really know any of the kids very well.... Then it goes a few days before I see them again and so it's hard to get to know them and have that relationship that kind of builds.... It's easier when you have fewer students.

Another teacher in her third year in this model similarly indicated that behavior management was a challenge. Although it might be expected that classroom management might improve after having students several years in a row, these specialists did not indicate that this challenge was alleviated with this model.

A common concern with models of ECS is the ability of a specialist to know the whole child and address each child's needs appropriately (Heathers 1961). There is an anticipated inverse relationship between the number of students and the ability to know the whole child, such that this ability decreases with an increase in the number of students. Interview data from this study support this expectation for specialists in model F. One ESS in this model remarked:

Keith: I do talk with some teachers about certain issues that are coming up with certain students, so we do have 
some dialogue once in a while about what would be effective practice or what's worked because they know them better than I do. They have more time with them.

Their knowledge of their students seems more limited than that of those who have the students more often or for longer periods of time during the day.

In contrast, an EMS (model B) at the same school described his collaboration with his team members differently, with a whole-child emphasis:

Matt: So with my partner teacher, we collaborate around other aspects of the students, academics or lives, more whole-child stuff. I set up an excellent student work bulletin board in which I was putting up examples of excellent work ... and so that's been nice to see some of their work and get a better whole picture of who they are as a student.

Although model F is characterized by a teacher who teaches academic content typically included in the content of a self-contained teacher (in contrast to PE or music), these ESS encounter challenges that may seem more familiar to specials teachers: not knowing all of their students on a whole-child level, learning names, and classroom management. These issues are interrelated; the sheer number of students impacts the specialists' abilities to know their students well, conduct multiple and meaningful assessments, and manage their classrooms.

Several prompts on the survey asked teachers to rate their knowledge of their students' strengths and weaknesses and their availability of time to meet the needs of their students. These data are summarized in Table 6.
In mathematics, there is only one significant comparison, knowing the students' strengths and weaknesses in English Language Arts, for which self-contained teachers rate themselves significantly higher than specialists. The science-focused groups demonstrate a statistically significant difference in favor of self-contained teachers for the same factor, as well as knowing when students are struggling with organization. ESS report significantly greater knowledge of their students' needs in science and a significantly greater ability to meet these needs. With the exception of these factors, there are no significant differences in the specialists and self-contained teachers' self-report data.

For the most part, both EMS and ESS report that they know their students' various academic, social, and emotional needs and are able to meet these needs as well as self-contained teachers. In fact, several specialists discussed ECS as providing an enhanced ability to meet students' social and emotional needs. One such benefit was the simple availability of more supportive adults in any given student's life:

Amy: There's three of us on the team. I think that's helpful for students that maybe don't necessarily bond with the one teacher.... If there's something going on, sometimes they feel safer with one teacher over the other to talk to them it seems.

In a similar vein, other team teachers described the value of having multiple people watching out for potentially at-risk students:

Melia: There's been students we've been concerned about - not just academically but really concerned

Table 6 Knowing and meeting the needs of the whole child

\begin{tabular}{|c|c|c|c|c|}
\hline \multirow{2}{*}{$\begin{array}{l}\text { Stem: Please provide your opinion about each of the following statements: } \\
1 \text {-strongly disagree } 6 \text { - strongly agree }\end{array}$} & \multicolumn{2}{|l|}{ Math } & \multicolumn{2}{|c|}{ Science } \\
\hline & EMS M & Self-contained M & ESS M & Self-contained $M$ \\
\hline I know the strengths and weaknesses of each of my students in math/science. & 5.29 & 5.41 & $4.89^{*}$ & $4.06^{*}$ \\
\hline I know when each of my students is struggling or succeeding in math/science. & 5.38 & 5.47 & 5.11 & 4.63 \\
\hline I have enough time with my students to meet their needs in math/science. & 3.58 & 3.35 & $4.00^{*}$ & $2.88^{*}$ \\
\hline I know the strengths and weaknesses of each of my students in English language arts. & $4.13^{* *}$ & $5.41^{* *}$ & $4.32^{* *}$ & $5.50^{* *}$ \\
\hline I know when one of my students is struggling with organization. & 5.42 & 5.71 & $5.25^{*}$ & $5.81^{*}$ \\
\hline I know the social and emotional needs of each of my students. & 5.42 & 5.41 & 5.26 & 5.69 \\
\hline I know when one of my students is having a bad day. & 5.71 & 5.71 & 5.58 & 5.94 \\
\hline I have enough time to meet the social and emotional needs of all of my students. & 3.33 & 3.35 & 3.37 & 3.38 \\
\hline $\begin{array}{l}\text { I have enough time to meet with other teachers and support staff about the } \\
\text { needs of my students. }\end{array}$ & 3.67 & 3.06 & 3.32 & 3.13 \\
\hline I have enough time to conference with the parents of each of my students. & 3.25 & 3.24 & 3.53 & 3.56 \\
\hline $\begin{array}{l}\text { I have enough time to contact parents of my students about their children's } \\
\text { academic, social, and emotional needs. }\end{array}$ & 3.42 & 2.71 & 3.63 & 3.25 \\
\hline
\end{tabular}
academic, social, and emotional needs. 
about their behavior, not they're active and disruptive but more like socially concerned and then we've been able... are you seeing this in your classroom as well?... I can think of three students that we have all had a pulse on much more this year in the first three months of school that I think we've been connected with.

Thus, having multiple adults looking out for students' social and emotional needs seems to be a potential benefit of ECS models. However, close and regular collaboration among team members was suggested as important to this process.

\section{Flexibility}

One theme that emerged from the analysis of focus group interviews was the lack of flexibility when engaged in an ECS model as compared to a self-contained classroom. With rigidly set times for each subject and students moving in and out of the classrooms, withinclassroom flexibility is diminished:

Melia (double participant, model E): I think the biggest challenge is when it's time to rotate you have to rotate. At 10:52 I need to have everything packed up, cleaned up, wiped off the board so the next class doesn't see what we just did because it's the same thing. And then we have... to go on and switch. There's been a couple of times when I wasn't quite ready and we're just, "All right, we've got to pack up."

When other teachers are dependent on classes of students switching at particular times, flexibility with extending time when needed is notably compromised.

Other specialists noted this same challenge: while ECS schedules have their benefits, having large blocks of time that can be flexibly utilized (as in a self-contained classroom) is not one of them. Similar challenges with flexibility surfaced consistently across the specialist interviews. Other teachers commented on the lack of flexibility for engaging in spontaneous activities, such as read-aloud or a dance party. Melia and another specialist at her school noted the inability to "steal time from something else" in order to extend time for other content areas.

Because flexibility emerged as a theme in the teacher focus group interviews, we included a prompt about this theme on the teacher survey. Our qualitative data was supported by data collected on the survey, but only in mathematics. Teachers were asked to respond to the statement, "I have flexibility in my schedule that allows me to engage students spontaneously in special opportunities." In math, self-contained teachers were strongly in agreement with this statement $(M=4.82$ on a $1-6$ scale). The mean for EMS was significantly lower $(M=3.63, p<0.01)$. In science, the comparison was not statistically significant.
In the sections above, we have described the six models of ECS that emerged from this research. In addition, we have presented results of the interviews and surveys of specialists and self-contained teachers and discussed some possible interpretations of these results. In the final section, we will discuss the implications of these findings on the theoretical framework, the limitations of this research, and the potential avenues for future research on ECS.

\section{Conclusions}

In the research reported here, we have sought to answer the following research questions related to elementary content specialization:

1. What models of ECS in mathematics and science are being implemented in local schools? What characteristics define these models?

2. What affordances and constraints exist in relation to ECS and ECS models, in comparison to a selfcontained model?

There is a remarkable dearth of research related to ECS or even the traditional, self-contained classroom teaching model that dominates elementary instruction. This research provides a framework for future research in this area by categorizing models of ECS and identifying and describing affordances and constraints related to its implementation.

As anticipated, we identified several different models of ECS in our sample (Table 3). Five of the six models that we have characterized here fall under the term team teaching and align with some of the descriptions found in the review of the literature (Strohl et al. 2014). Teachers work together as teams to provide core content instruction. In our sample, we identified teams consisting of two or three teachers; most of these teams teach students at the same grade level (models A-D); a few specialists work with teams of teachers across two grade levels (model E). Although we were able to recruit nine double participants (both EMS and ESS), we found that the specialists were not limited to specialization in STEM content. Instead, when teachers specialized in more than one content area (models B, D, and E), their content specializations are representative of the broad array of content for which elementary teachers are traditionally responsible.

In science, model F-science as a special-corresponded with the "pull-out" model described by Schwartz et al. (2000). Similarly, in our study, the ESS provide all science instruction at the upper elementary grade levels in separate science classrooms. In contrast, the classroom teacher is not expected to remain with the students. This may account for the classroom management issues that ESS engaged in this model report. 
Although we were able to identify six models from the small sample of this study, it is likely that there are more models currently in use. Our own past teaching experience suggests that there are elementary team teaching situations with four or five teachers serving as many classrooms of students. Also, there may also be models in which there are larger teams of teachers with smaller sub-teams within this larger team. For example, two two-teacher teams may combine to form a larger team of teachers, allowing for two EMS and/or ESS within a single larger team. Additional variations in teaming such as this may afford opportunities for content collaboration that are otherwise limited.

Engagement in ECS generally, and different models of ECS specifically, present various affordances and constraints. While self-contained classrooms have a high number of content areas to teach and preps for their classrooms, they have few potential transitions between classrooms and few students to monitor and support. In contrast, ECS afford fewer content areas for which to prepare yet a greater number of potential transitions between classrooms, and significantly more students. Differences between self-contained and ECS structures are magnified by certain models of specialization, such that these models can be placed along continua for these factors (Fig. 1). As might be expected, there seems to be a trade-off with these factors in ECS implementation, such that easing the role of the teacher in one area amplifies it in another.

Despite this, specialists in this study tend to speak of ECS quite favorably, primarily in regards to issues related to time. The results reported here provide empirical support for the increased time in planning instruction for ESS and EMS afforded by models of ECS. Specialists are significantly more likely to report that they have "enough time" to plan for all the subjects they teach, as well as their specialized content. Models of ECS seem to provide significantly more time in science instruction, and our results indicate that there are no significant differences between ECS and self-contained classrooms for time spent in transitions.

Specialists in all models indicate that the ability to focus on fewer content areas affords more planning time for the content and more effective use of professional development. Specialists contend that this leads to a higher quality of instruction. This reflects the limited literature in this domain, both theoretical (e.g., Reys and Fennell 2003) and empirical (e.g., Strohl et al. 2014).

It is important to note that affordances and constraints of ECS are not limited to the individual teacher. This study's findings do not support the concern of specialists being unable to know and address the needs of the whole child (Heathers 1961). Although there were some differences in specialists and self-contained teachers' ratings of their knowledge of their students and their abilities to meet students' needs, our quantitative analysis revealed few significant differences (Table 6). In fact, our interviews with specialists support previous findings (Strohl et al. 2014) that indicate that more teachers involved in students' instruction can provide benefits to both teachers and students.

Despite the lack of empirical research related to instructional models at the elementary level, there is a wide variety of models that surface in practice. A variety of factors may contribute to teachers' and administrators' decisions to engage in ECS. The research presented here may provide elementary educators with some framework for how instruction of core content areas might be shared between teachers. The structure of each of these models enables particular affordances and constraints, as depicted in Fig. 1. These continua of factors may support educators in their decision-making as they consider alternative instructional arrangements to the traditional, self-contained model.

Although we have characterized five of the six models here as team teaching models, it may also be important for educators to revisit the notion of the collaborative specialist model when considering alternatives to selfcontained classrooms (Nelson and Landel 2007). A significant emphasis of collaborative specialist models is collaboration around students and content. Although some specialists in this study indicated that they collaborated around shared students, specialists also reported isolation regarding content collaboration. To make team teaching most effective, it may be important to explicitly plan for collaboration around both content and students.

We consider the findings presented here a significant first step in describing models of ECS and understanding affordances and constraints related to ECS and specific models. In the final section, we examine some limitations to this research and suggest areas for future empirical research that will continue to move our understanding of ECS forward.

\section{Limitations and further research}

One limitation of this study is the small sample of specialists in mathematics and science and the potential limit to the types of models we were able to identify. Additionally, none of our specialists teach in large, urban, elementary schools. It may be that research with larger schools will yield larger teams of teachers or multiple teams of teachers within a grade level. Research on a larger scale is needed to verify the models found in this study. Expansion (e.g., models E and F) or consolidation (e.g., models A-D) of the models presented here may be possible with additional research.

Although the identification of additional models is possible, it is also likely that there is a ceiling to the 
number of possible models. Because there are limited core content areas to teach, there is a limitation to the number of teachers that may be practical on a particular team. Thus, it may be evident in future studies that there is a classification scheme for ECS models, such that team teaching models are first classified as withinor across-grade, and then by the number of core content teachers that share students.

The results reported here are also limited by the selfreport nature of the interview and survey data. However, future studies may seek to corroborate these findings through direct observations or other methods of recording teachers' time in planning and teaching. Modelspecific issues related to time may also be exposed through larger-scale studies. Future studies may also consider collecting data from other stakeholders. For example, parent and student surveys may provide more data to construct a more complete picture on specialists' abilities to meet the needs of the whole child.

Finally, because our sample is limited by its high concentration of teachers in the upper elementary grades (3-5), further investigation in the primary grades is warranted. As suggested here, it is possible that elementary students are quite capable of negotiating ECS models, and more perspectives on students enable a team to meet students' needs. However, it is also possible that there is an age for which the self-contained classroom structure is more appropriate. This can only be resolved through further research with ECS in grades $\mathrm{K}-2$; the differentiation of models identified in this research may provide the framework to examine which models provide the social and emotional support needed by primary students.

Ultimately, it is important to determine if there is any impact of ECS on teachers' quality of instruction and students' learning. These research questions have significant practical and policy implications, as a positive impact on these outcomes may provide impetus for widespread reconsideration of the traditional, selfcontained instructional model in the elementary years. However, it may be that different models yield different results. Thus, the classification of models presented here is an important first step to broadening the discussion of ECS and presenting descriptions of models that may serve as an important framework for future research.

Additional empirical research related to elementary content specialization (ECS) is clearly needed. We hope that the models of ECS that have been identified through this research will contribute to the field by providing differentiation for models that have previously been lumped together and treated the same within the literature. In this paper, we have provided empirical support for some affordances that ECS provides and mixed results regarding its constraints. We encourage future researchers in this area to build on this work to develop a more robust understanding of ECS and its impacts on all stakeholders involved.

\section{Additional file}

Additional file 1: Supporting data. (XLSX $126 \mathrm{~kb}$ )

\section{Acknowledgements}

The authors would like to thank the teachers who participated in this research. The authors would also like to extend their gratitude to the members of the Every Day Every Child Advisory Board who offered invaluable feedback on prior versions of this manuscript.

\section{Funding}

This material is based upon work supported by the National Science Foundation under Grant No. DRL-1316520. Any opinions, findings, and conclusions, or recommendations expressed in this material are those of the author(s) and do not necessarily reflect the views of the National Science Foundation.

\section{Availability of data and materials}

Qualitative data sources: because teacher participants may be identified based on their interview transcripts, these will not be made publicly available. Quantitative data sources: the dataset supporting the conclusions of this article is included within its Additional file 1.

\section{Authors' contributions}

The first two authors, KAM and JAB, contributed to the writing of this manuscript. KAM is the principal investigator on the grant for this project, and JAB is a research associate partially funded through this grant; as such, they have contributed substantially to the project's design and implementation, including data collection and analysis. CO and RP are co-principal investigators on the grant and as such have contributed to the analysis and interpretation reported here, as well as the editing and revisions of this manuscript. All authors read and approved the final manuscript.

\section{Authors' information}

KAM is an associate professor of mathematics education at the Western Washington University and is a former elementary and middle grades mathematics classroom teacher. In her current position, she works with preservice and inservice elementary and middle school classroom teachers to deepen their understanding of mathematical content and to improve their teaching practices.

$J A B$ is an educational researcher and program evaluator in the Science, Mathematics, \& Technology Education program at the Western Washington University. He is interested in science teaching and learning at all levels (primary grades through post-secondary and beyond) as well as educational uses of technology and media. Prior to earning his doctorate, he worked as a high school biology teacher.

$\mathrm{CO}$ is professor of education at the Western Washington University. Her research interests focus on elementary preservice teacher education in science. She has been co-PI and PI of many grants including the North Cascade and Olympic Science Partnership (2004-2010) and Models of Research-based Education for Teachers (2011-present).

$\mathrm{RP}$ is the CEO of the Mathematics Education Collaborative (MEC) and director of the MEC MSP: Preparing a Next Generation of Mathematics Teacher Leaders for Washington State. She is the co-author of Making Number Talks Matter (Stenhouse 2015), and author of Mathematical Power: Lessons from A Classroom (Heinemann 1993). RP was the director and co-author of the NSF supported workshop series Building Support for School Mathematics: How to Work with Parents and the Public (Heinemann 2006).

\section{Competing interests}

The authors declare that they have no competing interests.

\section{Author details}

${ }^{1}$ Western Washington University, Bellingham, USA. ${ }^{2}$ Mathematics Education Collaborative, Inc., Ferndale, USA. 
Received: 7 June 2016 Accepted: 24 August 2016

Published online: 08 September 2016

\section{References}

Chan, T. C., \& Jarman, D. (2004). Departmentalize elementary schools. Principal, 84(1), 70.

Chan, T. C., Terry, D., \& Bessette, H. (2009). Fourth and fifth grade departmentalization: a transition to middle school. Journal for the Liberal Arts and Sciences, 13(2), 5-13.

Gerretson, H., Bosnick, J., \& Schofield, K. (2008). A case for content specialists as the elementary classroom teacher. The Teacher Educator, 43, 302-314.

Gomez, L., \& Gomez, R. (2015). Dual language training institute. Retrieved May 1 , 2015, from http://dlti.us/index.html

Heathers, G. (1961). Field research on elementary school organization and instruction. Journal of Educational Sociology, 34(8), 338-343.

Hood, L. (2009). "Platooning" instruction: districts weigh pros and cons of departmentalizing elementary schools. Harvard Education Letter, 25(6), 1-6.

Horizon Research, Inc. (2012). 2012 National survey of science and mathematics education: science teacher questionnaire. Retrieved February 16, 2014, from http://www.horizon-research.com/2012nssme/sample-page/instruments/

McGatha, M. B. (2009). Mathematics specialists and mathematics coaches: what does the research say? Retrieved from http://nctm.org/uploadedFiles/ Research_News_and_Advocacy/Research/Clips_and_Briefs/Research_brief_ 13_coaches.pdf

McGatha, M. B., \& Rigelman, N. R., eds. (in press). Elementary mathematics specialists. Association of Mathematics Teacher Educators (AMTE).

McGatha, M. B., Davis, R., \& Stokes, A. (2015). Impact of mathematics coaching on teachers and students. Retrieved from http://www.nctm.org/Research-andAdvocacy/Research-Brief-and-Clips/Impact-of-Mathematics-Coaching-onTeachers-and-Students/

McGrath, C. J., \& Rust, J. O. (2002). Academic achievement and between-class transition time for self-contained and departmental upper-elementary classes. Journal of Instructional Psychology, 29(1), 40-43.

Nelson, G. D., \& Landel, C. C. (2007). A collaborative approach for elementary science. Educational Leadership, 64(4), 72-75.

Reys, B. J., \& Fennell, F. (2003). Who should lead mathematics instruction at the elementary school level? A case for mathematics specialists. Teaching Children Mathematics, 9(5), 277-282.

Sandler, J. O. (2003). Lest science be left behind. Education Week, 22(29)

Schwartz, R. S., \& Gess-Newsome, J. (2008). Elementary science specialists: a pilot study of current models and a call for participation in the research. Science Educator, 17(2), 19-30

Schwartz, R. S., Lederman, N. G., \& Abd-El-Khalick, F. (2000). Achieving the reforms vision: the effectiveness of a specialists-led elementary science program. School Science and Mathematics, 100(4), 181-193.

Strohl, A., Schmertzing, L., \& Schmertzing, R. (2014). Elementary teachers' experiences and perceptions of departmentalized instruction: a case study. Journal of Case Studies in Education, 6, 1-18.

Wu, H.H. (2009). What's sophisticated about elementary mathematics? American Educator, 33(3), 4-14.

\section{Submit your manuscript to a SpringerOpen ${ }^{\mathcal{O}}$ journal and benefit from:}

- Convenient online submission

- Rigorous peer review

- Immediate publication on acceptance

- Open access: articles freely available online

- High visibility within the field

- Retaining the copyright to your article

Submit your next manuscript at $\gg$ springeropen.com 